\author{
Asian Journal of \\ Medical and Biological Research \\ ISSN 2411-4472 (Print) 2412-5571 (Online) \\ www.ebupress.com/journal/ajmbr
}

\title{
Article \\ Comparative evaluation of recombinant LigB based latex agglutination test with microscopic agglutination test for the diagnosis of wildlife leptospirosis
}

\author{
Yosef Deneke ${ }^{1}$, Rajib Deb ${ }^{2}$ and S. M. Lutful Kabir ${ }^{3}$ \\ ${ }^{1}$ School of Veterinary Medicine, Jimma University College of Agriculture and Veterinary Medicine, Jimma, \\ Ethiopia \\ ${ }^{2}$ Scientist (SS) \& Officer, I/C ITMU ICAR-Central Institute for Research on Cattle, Indian Council of \\ Agricultural Research, Grass Farm Road, Meerut-250 001,Uttar Pradesh, India \\ ${ }^{3}$ Department of Microbiology and Hygiene, Bangladesh Agricultural University, Mymensingh-2202, \\ Bangladesh
}

"Corresponding author: Yosef Deneke, Jimma University College of Agriculture and Veterinary Medicine, P.O. Box 307, Jimma, Ethiopia. E-mail: yosefdeneke@yahoo.com

Received: 05 August 2020/Accepted: 17 September 2020/ Published: 30 September 2020

\begin{abstract}
In the present study a comparative evaluation microscopic agglutination test with rLigB protein based latex agglutination test was carried out, which is a cross reacting lipoprotein able to detect acute infection caused by any pathogenic leptospiral serovars. It was employed for serodiagnosis of leptospirosis. The $46 \mathrm{KDa}$ 6X His tagged LigB protein, obtained by IPTG induction of recombinant $E$. coli M15 cells containing the Nterminal region of LigB gee in ${ }_{\mathrm{P}} \mathrm{QE} 30$ expression vector, was purified by Ni-NTA affinity chromatography and adsorbed on latex bead surface for performing latex agglutination test against Leptospirosis suspected wildlife field sera. A total of 80 wildlife sera samples were collected, including 27 wild feline sera samples (18 tigers, 8 lions, and 1 jaguar) obtained from Chhatbir zoo, Chandigarh, 42 sera samples ( 8 tigers, 4 lions and 6 leopards, 2 cheethals, 1 black buck, 12 buffaloes and 9 zoo staff) were received from Jodhpur zoo Rajasthan, 8 sera samples (4 tigers, 3 leopards, 1 lion) from Van Vihar National park, Bohpal, Madhya Pradesh and 3 sera samples (2 lions and 1 tiger) received from Biwani Mini zoo, Haryana, India. The result showed that sera were tested positive by rLigB based LAT, which were reconfirmed using microscopic agglutination test (MAT). The results from LAT were in concordance with MAT. In conclusion, rLigB based LAT is a rapid, pen site, reliable diagnostic tool of high sensitivity and specificity, under laboratory and field conditions, for the detection of Leptospirosis.
\end{abstract}

Keywords: wildlife; leptospirosis; LigB; MAT; rLigB based LAT

\section{Introduction}

Leptospirosis is considered as an important reemerging, ubiquitous zoonotic disease worldwide, both developing and developed countries and the incidence of which is uncertain and it is underestimated (Faine, 1982; Vijayachari et al., 2008). The risk of infection is occurring due to contact with contaminated environments, infected wild animals as well as with synanthropic animals and rodents (Tilahun et al., 2013). The disease can be directly transmitted through contact with secretions, blood or urine of infected animals, or indirectly through water contaminated mainly with urine of reservoir animals (Bharti et al., 2003).

Global warming that leads to extreme weather events such as cyclones and floods, increased rainfall, and increased world population and urbanization are considered as the factors associated with the upsurge in the incidence of leptospirosis, as well as the magnitude of outbreaks (Hartskeerl et al., 2011). Generally, the prevention of leptospirosis can be considered an excellent example of "One Health", where the relationship between humans, animals and ecosystems needs be considered to better understand and manage the disease. 
Subsequently, any research and control effort requires a truly multidisciplinary and coordinated approach (Jancloes, et al., 2014).

In domestic animals, especially in dairy cattle. leptospirosis is an important cause of abortion, still birth, infertility, birth of weak calves, agalactia and death (Haake et al., 1998; Bhari et al., 2003; Theirmann,1984; Murray,1990;Cole, et al.,1972). In case of dogs the symptoms include fever, vomiting, dehydration, hepatitis, nephritis and death (Srivastava et al., 2006). In hoses, the important manifestation of leptospiral infection are abortion snd uveitis (Palaniappan, et al., 2002). The primary reservoir hosts for most Leptospira serovars are wild mammals, particularly rodents. Reservoir hosts among domestic animals includes cattle, dogs, sheep and pigs and they may act as carriers for several months (temporary carrier) while rodents usually remain carrier throughout their life (permanent carrier). Rodents are therefore considered as the major reservoir of infection (Waktole et al., 2016). The specific reservoir hosts vary with the serovar and the geographic region. Disease in reservoir hosts is more likely to be asymptomatic, mild or chronic (OIE, 2005).

Diagnosis of leptospirosis is very difficult in the early stage of the disease because, the intial symptoms are often indistinguishable from the other febrile illnesses. Anicteric leptospirosis is usually misdiagnosed as malaria, enteric fever, influenza or polynephritis. Icteric leptospirosis may be confused with viral hepatitis, septicemia with jaundice and malaria. For diagnostic purpose, the culture of leptospirosis from body fluids is the most demonstrative approach, but the technique can take up to two months and is very laborious. Even though, Dark Ground Microscopy (DGM) appears to be a simple and rapid procedure, the concentration of the organism present in the blood during acute stage of the disease is too low to allow detection by direct microscopy. The leptospiral shedding in urine is intermittent. Moreover serum proteins or cell fragments may mimic leptospires. Even experienced personnel may be confused with these artefacts (Vijayachari et al., 2001). Considering the problem in isolation or demonstration of leptospires in clinical samples, emphasis has been largely laid on serodiagnosis.

Microscopic Agglutination Test (MAT) has been the serological test of choice for the diagnosis of Leptospirosis and is also considered to be the gold standard test for detecting leptospirosis. The test is highly sensitive, serovar serogroup specific and performed on a paired sera collected from acute and convalescent cases. MAT is therefore useful for epidemiological purpose since it gives clear idea regarding the circulating serovars in endemic regions. MAT shows and find out a sero-conversion or a four-fold rise in antibody titer, on sera collected during the acute and convalescent stage of the disease, which is the evidence of current or recent infection (Vijayachari et al., 2001). Since collection of convalescent serum sample is difficult in routine practice, several disease investigator usually consider a titer of 1 in 100 as a significant titer of diagnosis without considering the endemicity or baseline titers in the community.

Microscopic agglutination test, however, requires the use of several leptospiral serovars in their active growth phase. But the maintenance of their culture is difficult, expensive, tedious and time consuming (Thiermann, 1983; Cousins et al., 1985; Bolin et al., 1989). The danger of acquiring the infection to laboratory technicians while handling the live leptospiral antigen, the cumbersome mechanism of recording the results and the need for paired sera samples to confirm the disease which delays disease diagnosis has made it difficult to adopt it as a routine lab test. When the sera are collected from a patients in the early phases of the disease or when the patient is infected with a serovar which is not included in the test, MAT, additionally can give false negative test result. It has been reported that MAT gives also false positive test result, therefore low MAT titers need to be judged with some degree of caution since cross reactive antibodies in patients with syphilis, relapsing fever, Lymes disease, enteric fever, Dengue and malaria may give a titer of 1:80. MAT cannot distinguish between IgM antibodies indicative of current infection and IgG antibodies which are indicative of previous infection. Further, MAT is unable to differentiate between vaccinated and naturally infected animals sera and gives positive test result to both cases, which suggests that it is not used as DIVA based strategy.

Therefore, more widely acceptable approach of serodiagnosis like ELISA, LeptDipstck, Lepto-dri-dot, Leptolateral flow, Latex agglutination test have been developed, which take the advantage of using genus specific proteins present in the outer membrane of the pathogenic leptospiral organism (Guerriro et al., 2001; Sehgal et al., 1999 and 2003; Vijayachari et al., 2002).

There are three classes of leptospiral outer membrane proteins (OMPs) which have been identified and used for diagnostic purposes. The most abundant class comprises the outer membrane lipoproteins which includes immune-dominant protein antigen LipL32 (Haake et al., 2000), Lip L36, which is down regulated protein in vivo (Haake et al.,1998) LipL48 (Haake and Matsungea, 2002), LipL41 which is surfaced exposed (Shang, et al.,1996) and bacterial immunoglobulin like domain proteins Lig A and LigB (Matsunga et al., 2003).

The antigens which are well characterized for its diagnostic potential so far are LipL32 and LipL41 (Branger et al., 2001). Apart from these two lipoproteins, LigA and LigB proteins are drawing much attention. Anti-LigB 
IgM antibodies were found in sera of $92 \%$ of patients during the acute phase leptospirosis (Croda et al., 2008). The research workers opined that the use of these markers may aid the prompt and timely diagnosis required to reduce the high mortality associated with severe form of the disease. Moreover, recent studies indicated the use of N-terminal conserved region of LigB protein is useful for discriminating between naturally infected and vaccinated animals (Palaniappan et al., 2004). Therefore the aims of the present study were 1) to standardize a diagnostic test like, latex agglutination test using recombinant LigB protein with sera samples collected from field 2) to comparatively determine the efficacy of rLigB latex agglutination test and microscopic agglutination test.

\section{Materials and Methods}

\subsection{Serum samples}

A total of 80 wildlife sera samples were collected, including 27 wild feline sera samples (18 tigers, 8 lions, and 1 jaguar) obtained from Chhatbir zoo, Chandigarh, 42 sera samples ( 8 tigers, 4 lions and 6 leopards, 2 cheethals, 1 black buck, 12 buffaloes and 9 zoo staff) were received from Jodhpur zoo Rajasthan, 8 sera samples (4 tigers, 3 leopards, 1 lion) from Van Vihar National park, Bohpal, Madhya Pradesh and 3 sera samples ( 2 lions and 1 tiger) received from Biwani Mini zoo, Haryana, India.

\subsection{Recombinant LigB protein expression and coating on latex beads}

A set of primers has been designed in order to express the $\mathrm{N}$-terminal conserved region of LigB gene, targeting a $1200 \mathrm{bp}$ long region of the $\operatorname{LigB}$ gene. A polymerase chain reaction was performed to amplify the $1200 \mathrm{bp}$ long conserved $\mathrm{N}$-terminal region of $\mathrm{LigB}$ gene. The amplicon was extracted from gel according to manufacturer instruction. Using the PCR product as a template, a nested PCR was performed using a set of internal primers which gave rise to a product of $600 \mathrm{bp}$ by length. The $1200 \mathrm{bp}$ amplicon was then inserted in to TA cloning vector pTZ57R by using DNA ligase enzymes. This recombinant vector was used to transfer competent $E$. coli $\mathrm{DH} 5 \alpha$ cells treated with chilled $0.1 \mathrm{M} \mathrm{CaCl}_{2}$ solution. Then, the recombinant cloned obtained were plated on Luria Bertani ampicillin plate to select the positive clones. In order to confirm the recombinants colony PCR and restriction digestion (RE) of the vector using SacI and HindIII enzymes were done. The insert released from pTZ57R vector was ligated to $\mathrm{pQE30}$ expression vector treated with the same set of RE enzymes and was transformed in to competent M15 cells of E. coli and the recombinant obtained were plated on LB ampicillin plates containing kanamycin. Then, colony PCR and RE digestion of the pQE30 vector using SacI and HindIII enzymes were also done for confirmation. The confirmed recombinant cells were used for expression of LigB gene by inducing the cells with $1 \mathrm{mM}$ Isopropyl B-D-1-thiogalactopyranoside (IPTG) during the $\log$ phase of growth and SDS-PAGE was then performed to check for the expression the recombinant protein. The leptospiral immunoglobulin like B protein appeared as a thick band at the expected size of $46 \mathrm{KDa}$. Later the minimum concentration required for the induction of LigB protein was determined to be $0.1 \mathrm{mM}$ IPTG. The time kinetics for the recombinant protein in SDS PAGE staring from two hours after induction and after eight hours maximum amount of $\operatorname{LigB}$ protein was detected in SDS-PAGE. The production of the recombinant LigB protein in a large amount was achieved by inoculation a $0.5 \mathrm{ml}$ of bacterial culture in $100 \mathrm{ml}$ of LB broth containing ampicillin and kanamycin. The bacterial cells were harvested by centrifugation and the bacterial pellet obtained was dissolved in lysis buffer with a PH of 8.0 and kept in a rocking (horizontal shaker) platform for two hours. The lysis buffer containing lysed bacterial cells was then centrifuged at 10,000 rpm for 20 minutes. The clear supernatant obtained was passed tough NI-NTA agarose chromatography column. The 6X histidine tagged $\mathrm{N}$-terminal portion of the LigB protein helps the protein to bind to $\mathrm{Ni}$ present in the chromatography column. The wash buffer at a PH of 6.3 was used to wash away any unbound protein. The bound LigB protein was eluted using elusion buffer at a PH of 4.5. The presence of purified protein was then determined using SDS-PAGE and the fraction E3 - E6 $(0.5 \mathrm{ml}$ each) contained maximum concentration of the protein. A dialysis of these fractions against PBS was conducted to remove urea. The dialyzed protein was used to coat the latex beads were used which was used for performing latex agglutination test against field sera. These sensitized latex beads were stored at $4^{0} \mathrm{C}$ and used for performing LAT test against field sera suspected of Leptospirosis by detection of anti-LigB antibodies. LAT was carried out to test the immunoreactivity of LigB protein using wildlife sera samples collected from different Zoo in India.

\subsection{Microscopic agglutination test}

Microscopic agglutination test was employed to detect antibodies from a total of 80 wildlife sera collected from different parts of India, using 16 leptospiral serovars viz., Australis, Autumnalis, Ballum, Bataviae, Canicola, Cyanopteri, Dejasiman, Grippotyphosa, Hardjo, Hebdomadis, Icterohaemorrhagiae, Louisiana, Pomona, 
Pyrogenes, Javanica and Tarrasovi grown in Ellinghausen, McCullough, Johnson and Harris (EMJH) liquid media (Difco laboratories, USA) at $30^{\circ} \mathrm{C}$. Microscopic Agglutination Test (MAT) was performed as per the standard protocol described by Cole et al. (1972) with dilution of sera done serially from 1:50 to 1:3200 in phosphate buffered saline (PBS, $\mathrm{pH}$ 7.2) and sera were incubated at $30^{\circ} \mathrm{C}$ for $3 \mathrm{hr}$ with suspension of live Leptospira serovars having concentration $2 \times 108$ cells $/ \mathrm{ml}$. The positive reaction was characterized by agglutination of at least $50 \%$ of Leptospira cells.

\section{Results}

\subsection{Polymerase chain reaction amplification, $r$ LigB protein expression}

The result of PCR (1200 bp amplicon) confirming the N-terminal conserved region of LigB gene and nested PCR (600 bp amplicon) for confirming the PCR product were shown in Figure 1. The clones CL1, CL2, CL3, CL5, CL6 and CL8 expressed rLigB protein upon IPTG induction (Figure 2). The minimum concentration required for the induction of $\mathrm{LigB}$ protein was determined to be $0.1 \mathrm{mM}$ IPTG. The time kinetics for the recombinant LigB protein expression showed that detectable amount of recombinant protein was present in SDS PAGE starting from two hours after induction and after eight hours maximum amount of LigB protein was detected in SDS PAGE (Figure 3). SDS PAGE of purified rLigB protein was showed in Figure 4. The elution fractions E4-E6 $(0.5 \mathrm{ml}$ each) containing the maximum concentration of the protein obtained after purification of His-tagged LigB protein by Ni-NTA affinity chromatography is shown in Figure 5. Seropositivity of wild feline sera was shown in Figure 6. It has been confirmed that recombinant LigB protein as an immunodominant protein against which antibodies are produced in the host during the active infection and anti LigB antibodies are present in sera of infected animals in higher concentration.

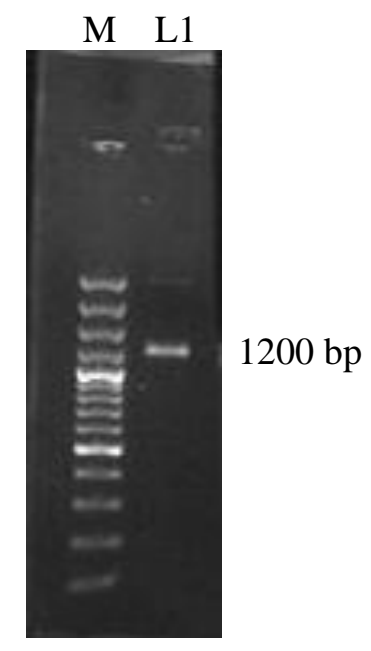

Figure 1. PCR amplification of Lig $B$ gene.

M: Molecular marker (100 bp); L1: Lig B gene amplicon (1200 bp).

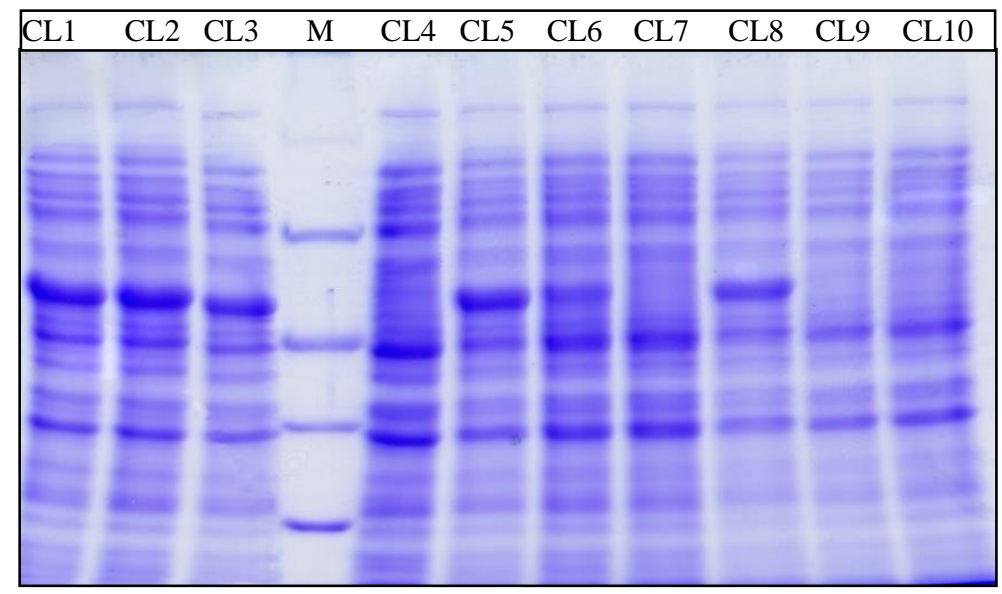

Figure 2. Clones expressing rLigB.

M: Marker; CL1-10: Clones 1-10. 


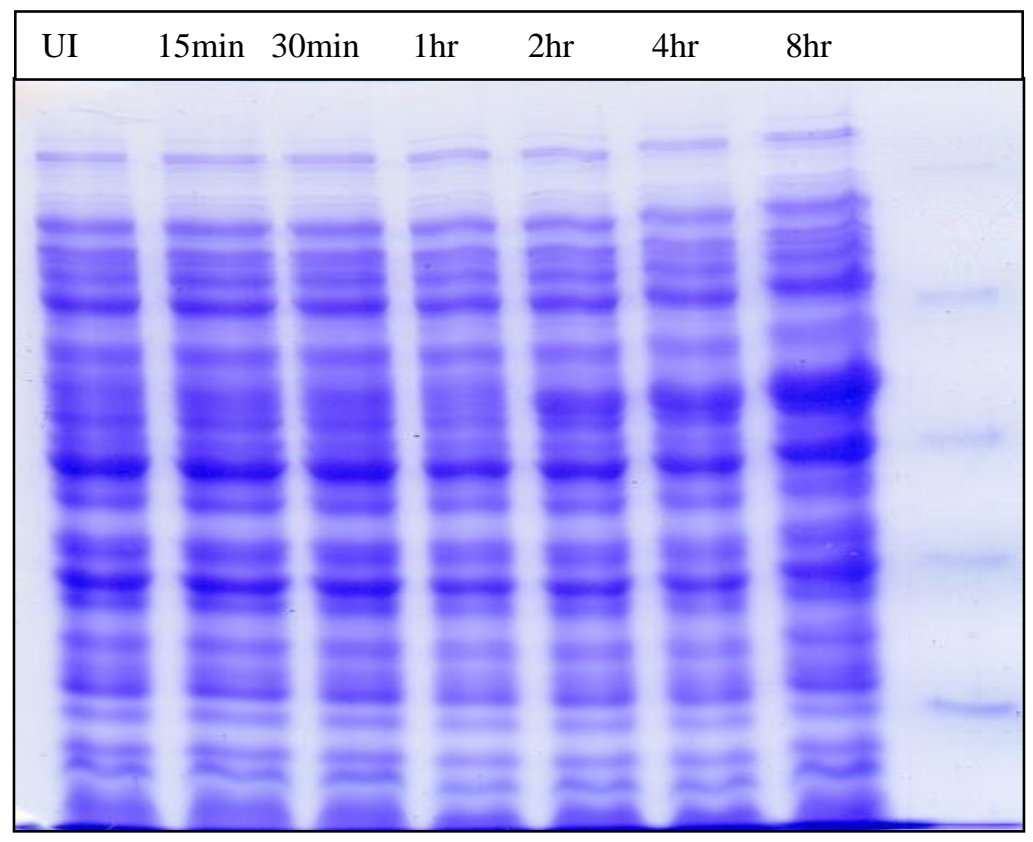

Figure 3. Expression kinetics of recombinant Lig B protein at various time intervals. UI: Uninduced

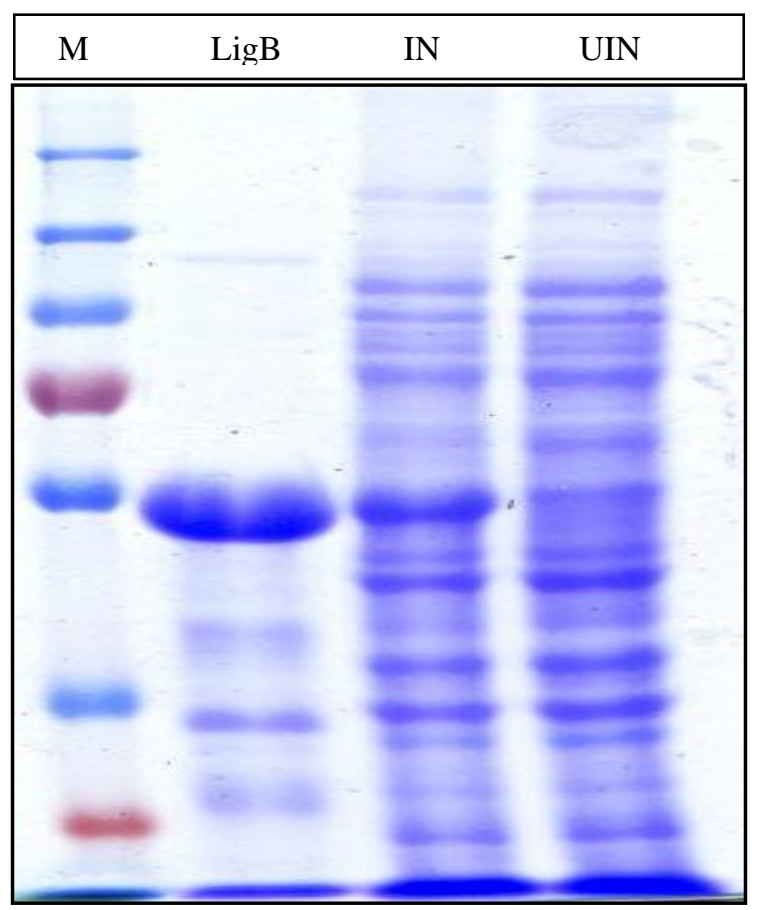

Figure 4. SDS-PAGE showing lysate of uninduced and induced. M15 cells along with purified Lig B protein M: Marker; LigB: Lig B protein; IN: Induced; UIN: Uninduced. 


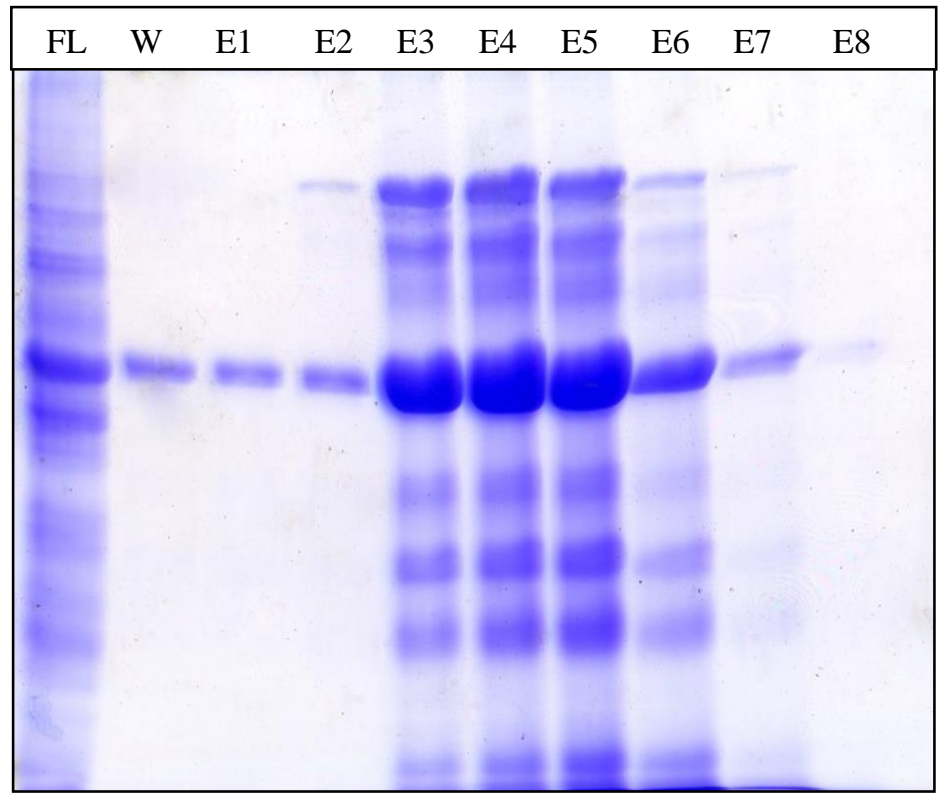

Figure 5. SDS-PAGE showing purified recombinant Lig B protein in various elusion fractions.

FL: Flow through; W: Wash; E1-E8: Elusion 1-8.

\subsection{Comparative evaluation of rLigB based LAT with MAT for the diagnosis of leptospirosis in wildlife sera samples}

A total of 27 wild life sera (18 Tiger, 8 lions and 1 jaguar) were obtained from zoological park Chhatbir, Chandigahr, India, of which all the lion sera, 15 tiger sera and 1 jaguar serum tested positive for Leptospirosis by rLigB LAT and MAT. L. icterohaemorrahigae was present in all the positive sera samples which in lion gave a maximum of titer of 1:800, while in tiger it gave a titer of 1:400. Only one lion serum tested positive for L. Pomona.

From Jhodpur zoo in Rajasthan, India, 42 sera samples (9 tiger, 4 lion, 2 leopard, 2 cheetahls, 1 black buck, 12 buffalo and 9 zoo staffs sera and 3 live rodents were obtained for Leptospirosis diagnostic. All the sera of 12 buffaloes whose carcass were fed to the wild felines tested positive using rLigB LAT and MAT , while the kidney and urine collected aseptically from the three live rodents tested negative on cultural examination, which indicated that the feeding of buffalo carcass without removing offal was responsible for the disease outbreak in the zoo. Seven tiger, all 4 lion, 2 leopard and 2 cheetthal sera tested positive for Leptospirosis by LAT, where as one black buck remains negative (Figure 6) and MAT. L. icterohaemorragiae was the main serovar involved in all animals while in Leopard, the serovar L. Pomona (Titer 1:800), L. grippotyphosa and $L$. australis were implicated. The humans who worked in close proximity with the wild feline showed a basal level sera titer (1:100) indicating exposure to the pathogens without any premonitory symptoms to the disease.

The result showed that sera were tested positive by rLigB based LAT, which were reconfirmed using microscopic agglutination test (MAT). The results from LAT were in concordance with MAT (Table 1). Microscopic Agglutination Test (MAT) has been the serological test of choice for the diagnosis of Leptospirosis and is also considered to be the gold standard test for detecting leptospirosis.

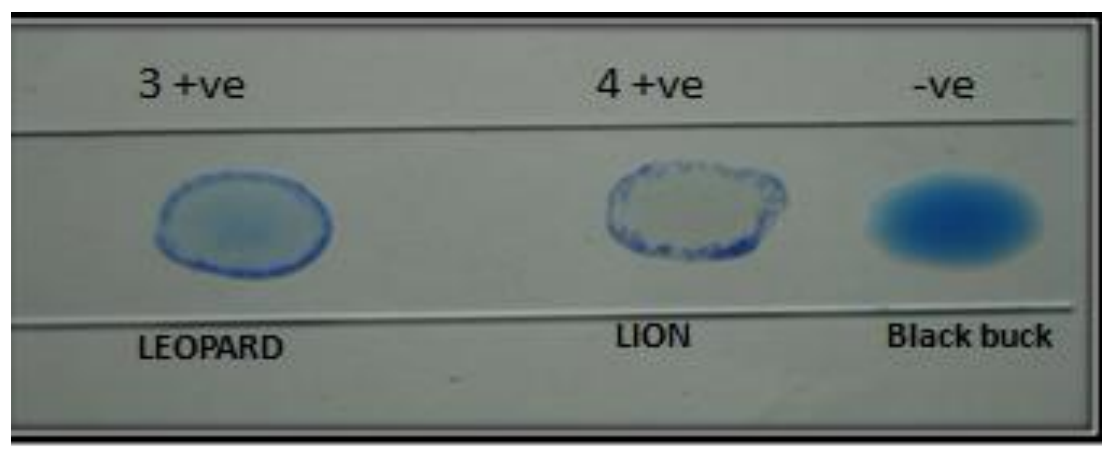

Figure 6. Seroreactivity of rLigB based LAT with wild feline sera. 
From Van Vihar national park Bhopal, MP, India, 8 wild life sera (4 tiger, 3 leopard and 1 lion sera) were received by which all the animals tested positive by LAT and MAT with $L$. icterohaemorragiae bring the serovar responsible for the disease.

Three sera samples (2 lion and 1 tiger) obtained from Bhiwari Mini zoo in Haryana, India, one lion and one tiger tested positive for Leptospirosis by LAT and MAT. The serovar implicated were L. icterohaemorrahigae and $L$. grippotyphosa.

Table 1. Evaluation of rLigB LAT to detect anti-leptospiral antibodies in wild animal sera as compared to MAT.

\begin{tabular}{|c|c|c|c|c|c|c|c|}
\hline Source of & Sample & Type of wild & No. of & & LAT & & IAT \\
\hline Sample & tested & animal & animals & Positive & Negative & Positive & Negative \\
\hline M.C. & 27 & Tiger & 18 & 15 & 3 & 15 & 3 \\
\hline Zoological & & Lion & 8 & 8 & - & 8 & - \\
\hline Park, & & Jaguar & 2 & 1 & - & 1 & - \\
\hline Chhatbir, & & & & & & & \\
\hline Johdpur Zoo. & 42 & Tiger & 9 & 7 & 2 & 7 & 2 \\
\hline Rajasthan & & Lion & 4 & 4 & - & 4 & - \\
\hline & & Leopard & 2 & 2 & - & 2 & - \\
\hline & & Cheetah & 2 & 2 & - & 1 & 1 \\
\hline & & Blackbuck & 1 & 1 & - & 1 & - \\
\hline & & Buffalo & 12 & 12 & - & 12 & - \\
\hline Vahn Vihar & 8 & Tiger & 4 & 4 & - & 4 & - \\
\hline National & & Lion & 1 & 1 & - & 1 & - \\
\hline Park, MP & & Leopard & 3 & 3 & - & 3 & - \\
\hline Bhiwani & 3 & Tiger & 1 & 1 & - & 1 & - \\
\hline $\begin{array}{l}\text { Mini Zoo, } \\
\text { Haryana }\end{array}$ & & Lion & 2 & 1 & 1 & 1 & 1 \\
\hline
\end{tabular}

\section{Discussion}

As a simple, sensitive pen site diagnostic test latex agglutination test employing recombinant LigB protein would serve for rapid and reliable diagnosis of Leptospirosis under field conditions.

This diagnostic test would not require the use of highly skilled labour and the test results would be very easy to interpret. Thus LAT can be recommended for field studies in which speed and simplicity are crucial (Raboni $e t$ al., 2004). When the field sera is mixed with rLigB coated latex beads, anti-LigB antibodies present in the sera of wild animals naturally infected by leptospirosis interact with the antigen leading to the formation of fine and clearly visible granular agglutination.

The intensity of the agglutination depends on concentration of the antibodies in a sera sample. Clearly visible granular agglutination indicates the presence of specific antibodies to leptospires. In stronger reactions due to sera of high antibody titre, fine granular clumps tend to settle at the edge of the circle and the reaction time to form fine granular clumps is lesser than 60 seconds. Agglutination that occurs beyond 2-3 minutes may be due to evaporation and should be treated as doubtful cases When Latex beads are sensitized with rLigB protein which are cross reactive lipoproteins found on the outer membrane of most pathogenic leptospiral serovars, this test would be able to detect infection caused by any pathogenic leptospiral serovars. Unlike MAT which employs live whole Leptospiral antigens which pose danger to the lab technician performing the test, LAT employing rLigB protein is completely safe and non-hazardous. The coated latex particles are stable for long periods at $4^{\circ} \mathrm{C}$ and this long shelf life and cost effectiveness of this test makes this test a very desirable diagnostic tool for detecting leptospirosis. Other potential advantages of rLigB based LAT include its portability, limited amount of generated biomedical waste. The test finds high level of application in developing countries such as India where it can be used in resource-poor settings, by investigators with only limited training. (Jackson, 2006)

The present study indicated that the sensitivity and specificity of recombinant LigB protein based latex agglutination test was comparable to microscopic agglutination test which is universally considered the gold standard test for diagnosis of leptospirosis. Latex agglutination test results were generally in concordance with 
MAT and it was also observed that a quantitative relation exists between both the tests. The sera samples reacting strongly showed titer of 1:800 or above by MAT invariably gave $+++/++++$ test result with $\operatorname{rLigB}$ based LAT while weakly and moderately reactive sera showed titer of 1:100 and 1:200 respectively by MAT gave + and ++ test result with $\mathrm{rLigB}$ based LAT

\section{Conclusions}

It can be concluded that, the rLigB based latex agglutination test having sensitivity and specificity comparable to microscopic agglutination test and also possessing the additional advantage of being to serve as a pen site diagnostic test, can be easily employed, in well established Veterinary hospitals as well as in mobile veterinary clinics operating in remote, resource-poor settings,

\section{Acknowledgements}

Yosef Deneke was the recipient of Ethiopian government scholarship to pursue his study in India. We are also thankful to the Director, IVRI, Izatnagar, India for providing the facilities to carry out this study.

\section{References}

Bharti AR, JE Nally, JN Ricaldi, MA Matthias, MM. Diaz, MA Lovett, PN. Levett, RH Gilman, MR Willing, E Gotuzzo and JM Vinetz, 2003. Leptospirosis: a zoonotic disease of global importance. Lancet Infect. Dis., 3: $757-771$.

Bolin CA, RL Zuerner and G Trueba, 1989. Comparison of three techniques to detect Leptospira interrogans serovar hardjo type hardjobovis in bovine urine. Am. J. Vet. Res., 50: 1001-1003.

Branger C, C Sonrier, B Chatrenet, B Klonjkowski, N Ruvoen- Clouet, A Aubert, G Andre-Fontaine and M Eloit, 2001. Identification of the hemolysis-associated protein 1 as a cross-protective immunogen of Leptospira interrogans by adenovirus mediated vaccination. Infect. Immun., 69: 6831-6838.

Cole J R, CR Sulzer and AR Pursell, 1972. Improved microtechnique for the leptospiral microscopic agglutination test. Appl. Microbiol., 25: 976-980.

Cousins DV, GM Robertson and L Hustas, 1985. The use of the enzyme-linked immunosorbent assay (ELISA) to detect the IgM and IgG antibody response to Leptospira interrogans serovar hardjo, pomona and tarassovi in cattle. Vet. Microbiol., 10: 439-450.

Croda J, J. Matsunaga, A Queiroz, A Hamma, RW Riley, DA Haake, MG Reis and AI Ko, 2007. Leptospira immunoglobulin-like proteins as a serodiagnostic marker for acute leptospirosis. J. Clin. Microbiol., 45: 1528-1534.

Faine S, 1982. Guidelines for control of leptospirosis. Geneva, World Health Organization.

Guerreiro H, J Croda, B Flannery, M Mazel, J Matsunaga, M Galvao Reis, PN Levett, AI Ko and DA Haake, 2001. Leptospiral proteins recognized during the humoral immune response to leptospirosis in humans. Infect. Immun., 69: 4958-4968.

Haake DA, C Martinich, TA Summers, ES Shang, JD Pruetz, AM McCoy, KM Mazel and CA Bolin, 1998. Characterization of leptospiral outer membrane lipoprotein LipL36: downregulation associated with late-logphase growth and mammalian Infection. Infect. Immun., 66: 1579-1587.

Haake DA, G Chao, RL Zuerner, JK Barnett, D Barnett, M Mazel, J Matsunaga, PN Levett and CA Bolin. 2000. The leptospiral major outer membrane protein LipL32 is a lipoprotein expressed during mammalian infection. Infect. Immun., 68: 2276-2285.

Haake DA and J Matsunaga, 2002. Characterization of the leptospiral outer membrane and description of three novel leptospiral membrane proteins. Infect. Immun., 70: 4936-4945.

Hartskeerl R, M Collares-Pereira and W Ellis, 2011. Emergence, control and re-emerging leptospirosis: dynamics of infection in the changing world. Clin. Microbiol. Infect., 17: 494-501.

Jackson CH, MB Glass, MD Ari, SL Bragg, SL Branch, CU Whittington, CN Edwards and PN Levett, 2006. Evaluation of a commercial latex agglutination assay for the serological diagnosis of leptospirosis. J. Clin. Microbiol., 44: 1853-1855.

Jancloes M, E Bertherat, C Schneider, S. Belmain, C Munozanzi, R Hartskeerl, F Costa, J Denis and J Benschop, 2014. Towards a "One Health" Strategy against Leptospirosis. In: Planet@Risk, 2(3), Special Issue on One Health (Part I/II): 204-206, Davos: Global Risk Forum GRF Davos.

Levett PN, SL Branch and CN Edwards, 2000. Detection of dengue infection in patients investigated for leptospirosis in Barbados. Am. J. Trop. Med. Hyg., 62: 112-114.

Levett PN, 2001. Leptospirosis. Clin. Microbiol. Rev., 14: 296-326. 
Matsunaga J, MA Barocchi, J Croda, TA Young, Y Sanchez, I Siqueira, CA Bolin, MG Reis, LW Riley, DA Haake and AI Ko, 2003. Pathogenic Leptospira species express surface-exposed proteins belonging to the bacterial immunoglobulin super family. Mol. Microbiol., 49: 929-945.

Murray RD, 1990. A field investigation of causes of abortion in dairy cattle. Vet. Rec. 127: 543-547.

Office International des Epizooties (OIE), 2005. Institute for International Cooperation in Animal Biology. Iowa State University, College of Veterinary Medicine.

Palaniappan RU, YF Chang, SS Jusuf, S Artiushin, JF Timoney, SP McDonough, SC Barr, TJ Divers, KW Simpson, PL McDonough and HO Mohammed, 2002. Cloning and molecular characterization of an immunogenic LigA protein of Leptospira interrogans. Infect. Immun., 70: 5924-5930.

Palaniappan RU, YF Chang, F Hassan, SP McDonough, M Pough, SC Barr, KW Simpson, HO Mohammed, S Shin, P McDonough, RL Zuerner and JB Qu, 2004. Expression of leptospiral immunoglobulin-like protein by Leptospira interrogans and evaluation of its diagnostic potential in a kinetic ELISA. J. Med. Microbiol., 53: 975-984.

Raboni SM, MB Nogueira, VM Hakim, VTG Torrecilha, H Lerner and LRV Tsuchiya, 2004. Comparison of Latex agglutination with enzyme immunoassay for detection of rotavirus in faecal specimens. Am. J. Clin. Pathol., 117: 392-394.

Sehgal SC, P Vijayachari, S Sharma and AP Sugunan, 1999. LeptoDipstick - a rapid and simple method for serodiagnosis of leptospirosis in acute stage. Trans. Roy. Soc. Trop. Med. Hyg., 93: 161-164.

Sehgal SC, P Vijayachari, AP Sugunan and T Umapathi, 2003. Field application of Lepto-lateral flow for rapid diagnosis of leptospirosis. J. Med. Microbiol., 52: 1- 6.

Shang ES, TA Summers and DA Haake, 1996. Molecular cloning and sequence analysis of the gene encoding LipL41, a surface-exposed lipoprotein of pathogenic Leptospira species. Infect. Immun., 64: 2322-2330.

Sharma S, P Vijayachari, AP Sugunan and SC. Sehgal, 2003. Leptospiral carrier state and seroprevalence among animal population a cross sectional sample survey in Andaman \& Nicobar Islands. Epidemiol. Infect., 131: 985-989.

Srivastava SK, 2006. Prospects of developing leptospiral vaccines for animals. Indian J. Med. Microbiol., 24: 331-336.

Thiermann AB, 1984. Bovine leptospirosis: bacteriologic versus serologic diagnosis of cows at slaughter. American J. Vet. Res., 44: 2244- 2245.

Tilahun Z, D Reta and K Simenew, 2013. Global epidemiological overview of leptospirosis. Int. J. Microbiol. Res., 4: 9-15.

Vijayachari P, AP Sugunan and SC Sehgal, 2001. Role of Microscopic Agglutination Test (MAT) as a diagnostic tool during acute stage of leptospirosis in low and high endemic areas. Indian J. Med. Res., 114: 99-106.

Vijayachari P, AP Sugunan and SC Sehgal, 2002, Evaluation of Lepto dri-dot as a rapid test for the diagnosis of leptospirosis. Epidemiol. Infect., 129: 617-21.

Vijayachari P, AP Sugunan and A Shriram, 2008. Leptospirosis: an emerging global public health problem. Journal of Biosciences, 33: 557-69.

Waktole Y, G Bashahun and A Nejash, 2016. Leptospirosis in animal and its Public Health Implications, a review. World Appl. Sci. J., 34: 845-853. 